\title{
THE MECHANICAL PROPERTY RESPONSE OF TURBINE DISKS PRODUCED USING ADVANCED PM PROCESSING TECHNIQUES
}

\author{
Anthony Banik \\ Special Metals Corporation \\ Princeton, KY USA \\ Kenneth A. Green \\ Rolls-Royce Corporation \\ Indianapolis, IN USA
}

\begin{abstract}
Over the thirty years for which powder metal processing was applied in the production of superalloy turbine disk components, many advancements in the understanding of powder processing and applications have evolved. In this regard, a major shift to finer powder sizes has driven manufacturers to investigate advanced powder processing routes to minimize alloy costs. In addition, major advancements in understanding component temperature and strength capability have permitted improvements in designs that extend the ultimate performance of the turbine under extreme operating conditions. In this investigation, the powder UDIMET $\circledast$ Alloy 720 was produced using an advanced gas atomization nozzle in combination with process improvements consisting of hot isostatic pressing and low ratio extrusion to develop fine grain microstructures for subsequent isothermal forging to a low pressure turbine disk. The disks were evaluated both non-destructively to assess the ultrasonic inspection capability and destructively to demonstrate mechanical property capability.
\end{abstract}

\section{$\underline{\text { Introduction }}$}

Powder metal (PM) superalloys have been utilized in gas turbine engines for over thirty years. Initial processing for powder metal superalloys utilized a hot compaction plus extrusion conversion sequence. High extrusion ratios were employed to develop a fine grain billet microstructure ${ }^{1}$. The fine grain billet microstructures provided starting material suitable for slow strain rate, isothermal forging techniques. The subsequent near-net shape forging was then heat treated to produce high strength, fine grain disks used initially in military turbines. As powder processing became better understood, powder metal superalloy applications expanded to include the most advanced commercial and military engines. These highly stressed components continue to utilize many of the powder billet processing

UDIMET is a registered trademark of Special Metals Corporation. techniques established during the initial phases of powder development.

Concurrently with improvements in powder processing, modified superalloy compositions were being developed to meet the demands of advanced turbine engine designs. One alloy, UDIMET Alloy 720, has been developed for both powder metal processing and conventional ingot metallurgy processing routes. Thus, the alloy provides an excellent baseline material to assess the benefits of advanced powder metal processing techniques compared to a baseline ingot metallurgy processing technique.

In the 1960's, the powder compaction and extrusion operations were established on powder material produced using conventional atomization processes. These processes utilized argon gas atomization techniques and provided powder distributions that ranged in size from $180 \mu \mathrm{m}$ to $+30 \mu \mathrm{m}$ in diameter. The powder was then screened to restrict the coarse powder fraction and provide a means to control residual defect size in the material for life prediction methodologies. Typically, the powder was screened to provide $-150 \mu \mathrm{m}$ powder for consolidation and extrusion. High extrusion ratios provided refinement of the coarse powder structure and were thought to provide a dispersion of possible powder contaminants including organic and in-organic inclusions.

Low cycle fatigue tests have shown that the fatigue life of components can be significantly increased with the use of finer powder size. However, until recently, the costs for producing fine powder material has restricted applications to only the most critical hardware having the most demanding operating conditions relative to temperature and cyclic stress conditions.

An advanced atomization process incorporating a high yield nozzle (HYN) atomization process is presently being evaluated at Special Metals Corporation. The HYN has demonstrated the capability to increase the yields of fine superalloy powder in excess of $50 \%$. The increase in fine powder yields results in a direct reduction of powder

Superalloys 2000

Edited by T.M. Pollock. R.D. Kissinger. R.R. Bowman. 
manufacturing costs. With the fine starting powder material, additional cost reductions associated with the consolidation and extrusion operations can also be incorporated.

\section{Powder Characterization}

The powder material was produced in a production gas atomization unit using the high yield nozzle and screened to -270 mesh $(53 \mu \mathrm{m})$. Powder samples were obtained for characterization studies including chemistry, heavy liquid separation testing ${ }^{2}$ and water elutriation testing. The baseline chemistry (Table I) of the powder was consistent with production UDIMET Alloy 720 material produced using conventional ingot metallurgy or powder metallurgy techniques.

Table I The powder was produced to the standard UDIMET Alloy 720 composition. (in weight percent unless otherwise noted.)

$\begin{array}{cccccc}\mathbf{C} & \mathbf{C r} & \mathbf{C o} & \mathbf{M o} & \mathbf{T i} & \mathbf{A l} \\ 0.027 & 16.0 & 14.5 & 3.01 & 5.14 & 2.63 \\ \mathbf{W} & \mathbf{Z r} & \mathbf{B} & \mathbf{N i} & \mathbf{\mathbf { O } _ { 2 }} & \mathbf{N}_{\mathbf{2}} \\ 1.29 & 0.04 & 0.02 & \mathrm{Bal} & 190 \mathrm{PPM} & 9 \mathrm{PPM}\end{array}$

Heavy liquid separation (HLS) testing was performed to assess the frequency of inclusions present in a $0.4 \mathrm{~kg}(0.5$ lb.) powder sample. The particles are separated using a thallium formate solution followed by scanning electron microscopy to count and classify the inclusions. As indicated in Table II, the inclusions present were typical of those present during standard powder atomization.

Table II HLS testing revealed refractory type oxide particles.

\begin{tabular}{|c|c|c|c|c|c|c|c|c|c|c|}
\hline \multicolumn{10}{|c|}{} & \multicolumn{10}{|c|}{ Area (mil ${ }^{2}$ ) } & \multicolumn{7}{|c|}{ EDS (\%) } \\
\hline Type & $\boldsymbol{f}$ & Min. & Max. & C & O & Na & Mg & Al & Si & Ca \\
\hline $\mathrm{Al}$ & 12 & 1.12 & 7.33 & $>0$ & $>0$ & $=0$ & $=0$ & $>0$ & $>0$ & $=0$ \\
\hline $\mathrm{Mg}$ & 2 & 3.36 & 7.48 & $>0$ & $>0$ & $=0$ & $>=0$ & & & \\
\hline $\mathrm{Si}$ & 6 & 1.35 & 11.75 & $>0$ & $>0$ & $>0$ & $<5$ & $<5$ & $>10$ & $>0$ \\
\hline Other & 12 & 1.05 & 7.33 & & & & & & & \\
\hline
\end{tabular}

Water elutriation testing was performed on the powder material and provided very erratic results. The water elutriation test was established for coarse powder fractions or -150 mesh material. With the present material of -270 mesh product, powder samples for elutriation testing required reconstructing the original powder distribution prior to performing elutriation testing. The subsequent powder exhibited a high frequency of powder contamination from the additional powder handling and the results were considered inconclusive.

\section{Billet Manufacture}

The powder was consolidated using a hot isostatic press consolidation process in combination with a 3:1 extrusion process to a $152 \mathrm{~mm}$ (6") diameter billet. Testing of the billet material included large bar tensile (LBT) testing, metallographic evaluations, electron beam button analysis and ultrasonic inspection.

The LBT evaluations were performed on test samples obtained from the lead and tail end of each extrusion. As indicated in Figure 1, the LBT test results indicated that the powder material contained refractory materials typical of vacuum melted and atomized product. The area of the material at the fracture initiation site was similar to those evident during HLS testing of the powder material. The morphology of the material however was elongated as a result of the extrusion operation.

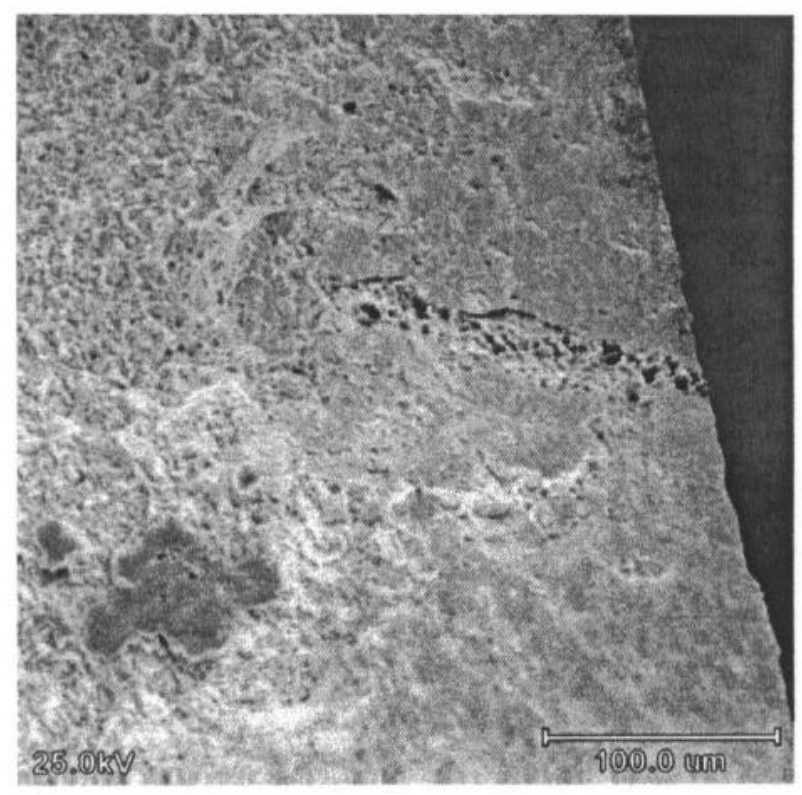

\begin{tabular}{|c|c|c|c|c|}
\hline Billet & Location & $\begin{array}{c}\text { Length } \\
\left(\mathrm{mil}^{2}\right)\end{array}$ & $\begin{array}{l}\text { Width } \\
\left(\text { mil }^{2}\right)\end{array}$ & $\begin{array}{l}\text { Area } \\
\left(\mathrm{mil}^{2}\right)\end{array}$ \\
\hline \multirow[t]{2}{*}{5306} & Lead & 110 & 45 & 5.6 \\
\hline & Tail & 170 & 28 & 5.9 \\
\hline \multirow[t]{2}{*}{5307} & Lead & 105 & 20 & 2.9 \\
\hline & Tail & 175 & 25 & 5 \\
\hline \multirow[t]{2}{*}{5311} & Lead & 155 & 40 & 6.3 \\
\hline & Tail & 130 & 30 & 4.5 \\
\hline
\end{tabular}

Figure 1 Powder processing tests revealed typical refractory materials associated with the primary melt operations that were elongated in the extrusion direction. 
Test samples were obtained from each extrusion for electron beam button testing. The samples were approximately $1 \mathrm{~kg}(2 \mathrm{LB})$ each. The test was performed using a drip melting process followed by a gradual reduction in power to provide for directional solidification of the button prior to total reduction of the power. This process permits floatation of the low-density oxide materials to the top center of the button for subsequent analysis.

Each button sample was evaluated for the raft size and composition of the materials that were evident at the button surface. As indicated in Figure 2, the composition of the raft is similar to materials observed during previous tests performed on the powder material.

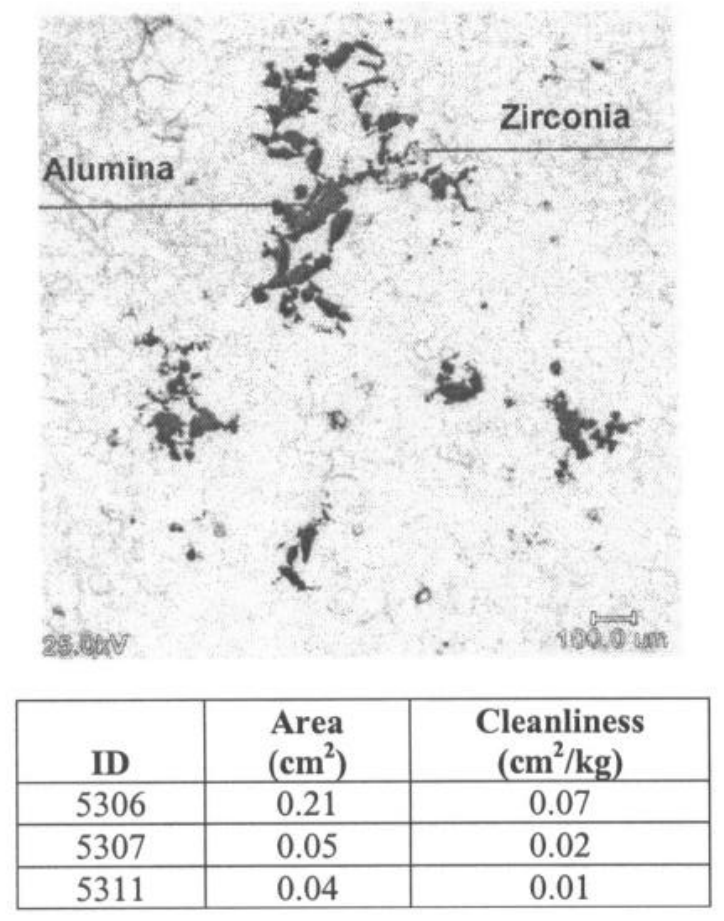

Figure 2. Alumina and zirconia were evident on the button surface.

Metallographic evaluations and ultrasonic response were typical of fine grain powder metal billet product using high extrusion ratios as indicated in Figure 3 . The grain size was assessed in the longitudinal direction at the lead and tail of each extrusion. The extruded product revealed ASTM 14 grain size at the center, mid-radius and edge locations after extrusion. The grain size of the low extrusion ratio product was similar to that obtained previously with an extrusion ratio of 6:1. Ultrasonic inspection of the billet material was performed to $10 \%$ of a No. 1 flat bottom hole (FBH) standard with no indications evident.

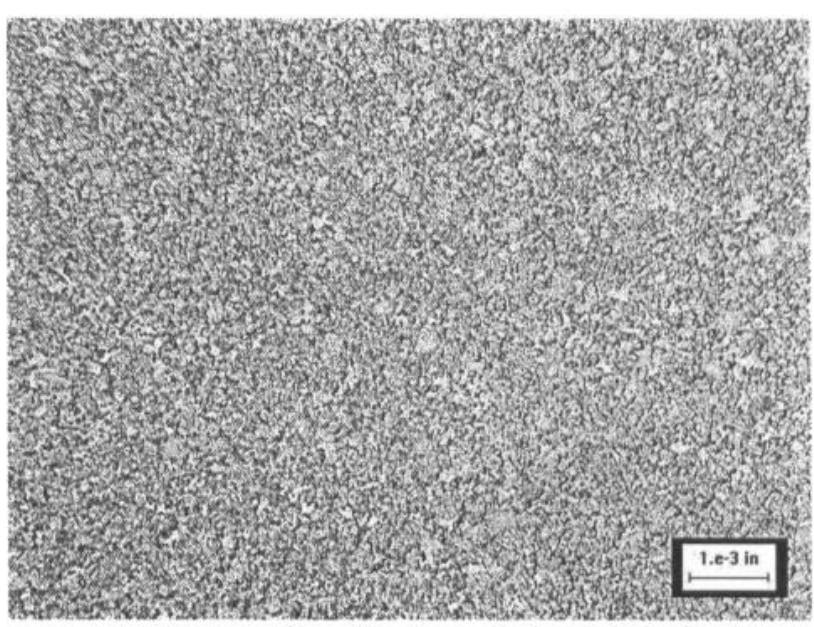

PM UDIMET Alloy 720 Extruded at 6:1 Reduction 152 mm (6") Diameter Billet

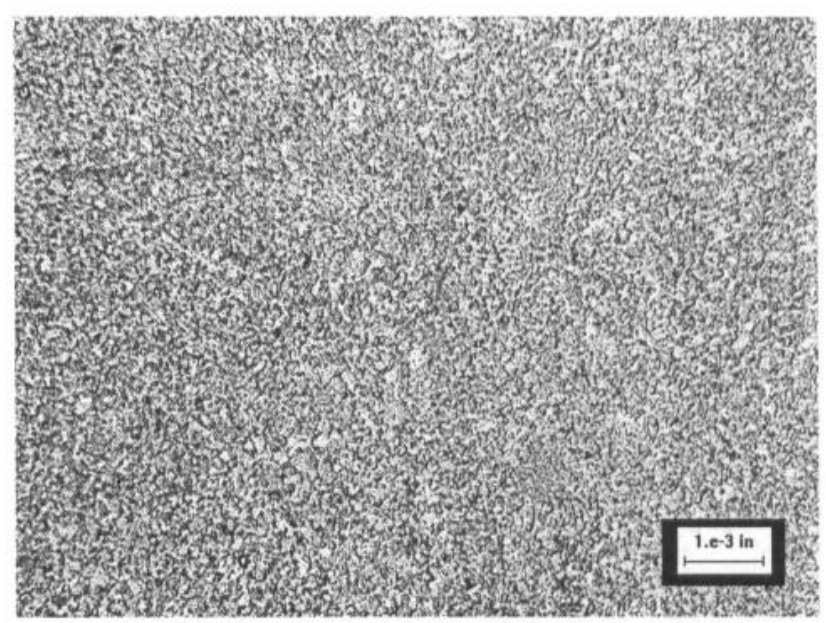

PM UDIMET Alloy 720 Extruded at 3:1 Reduction 152 mm (6") Diameter Billet

Figure 3. Metallographic evaluations indicated that the $3: 1$ reduction ratio provided a similar grain size to conventional product extruded at a ratio of $6: 1$.

The HYN powder billet material was subsequently isothermally forged by Ladish Company, Inc. into lowpressure turbine disks, ${ }^{3}$ as shown in Figure 4. The thermo-mechanical processing schedule was tailored to produce a damage tolerant microstructure, which offered a balance of tensile yield strength and fatigue crack growth resistant properties. To accomplish this, a subsolvus solution heat treatment in the range of $1121^{\circ} \mathrm{C}$ $\left(2050^{\circ} \mathrm{F}\right)$ to $1149^{\circ} \mathrm{C}\left(2100^{\circ} \mathrm{F}\right)$ was used to produce a controlled coarsening of the grain structure to a uniform size of ASTM 11. A standard two-step age cycle of $760^{\circ} \mathrm{C}\left(1400^{\circ} \mathrm{F}\right) / 8 \mathrm{hrs} .+649^{\circ} \mathrm{C}\left(1200^{\circ} \mathrm{F}\right) / 24$ hours produced the desired aging response to the gamma prime and carbide precipitates. 


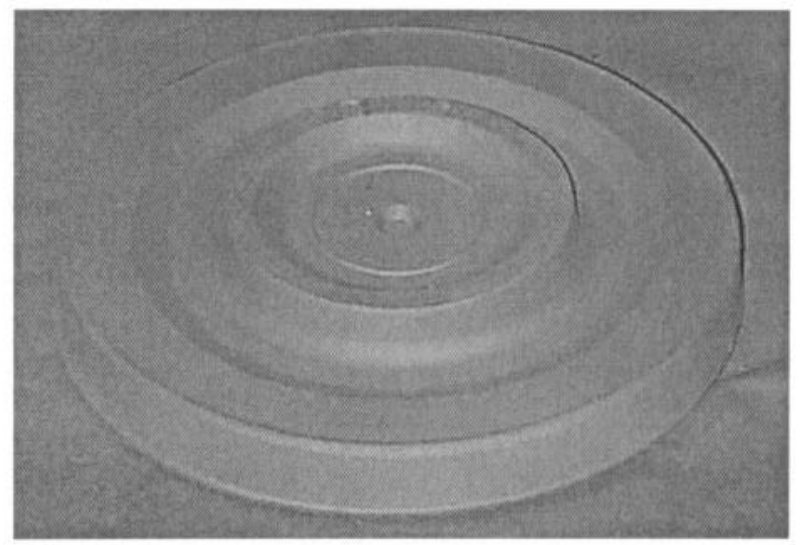

Figure 4. The powder billet was successfully isothermally forged into low-pressure turbine disks.

\section{$\underline{\text { Results and Discussion }}$}

The disks were evaluated nondestructively to assess ultrasonic resolution. All disks passed the inspection based on rejection criteria of a $10 \%$ of No. 1 flat bottom hole $(0.38 \mathrm{~mm} \mathrm{FBH})$ size. Mechanical property evaluations on the disks revealed the high yield nozzle atomized powder process in combination with the low extrusion ratio provided excellent high temperature tensile strength and ductility, as indicated by Figure 5 .

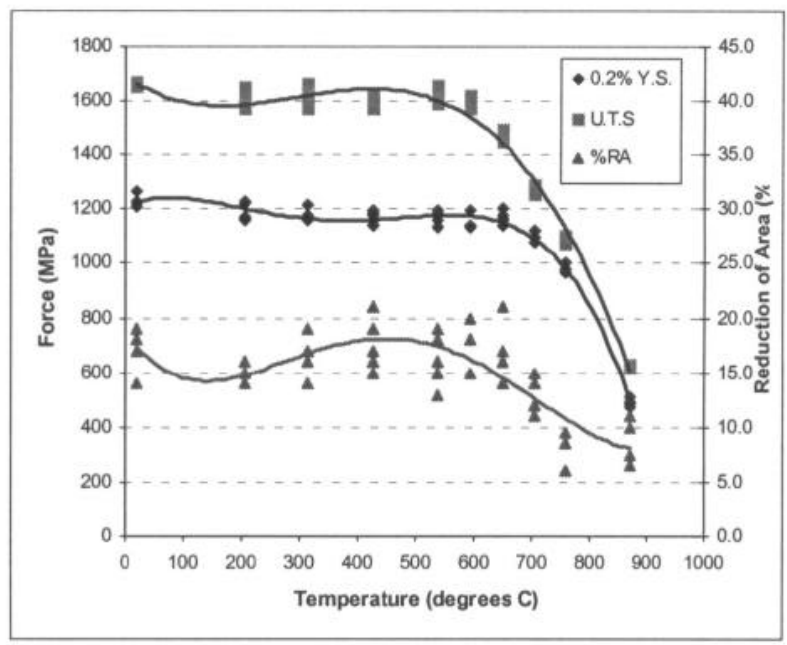

Figure 5. The PM UDIMET Alloy 720 disk exhibited excellent high strength tensile capability.

Low cycle fatigue (LCF) testing was performed at elevated temperatures for several R-ratios. The results at $538^{\circ} \mathrm{C}\left(1000^{\circ} \mathrm{F}\right)$ for $\mathrm{R}=0.0$ are plotted in Figure 6 with results of PM UDIMET Alloy 720 produced by conventional atomization, screened to -150 mesh and heat treated to a grain size of predominantly ASTM $14^{4}$. The data of both materials are comparable, although a slight difference is noted at the high strain rates, where the ASTM 14 material is slightly better than the ASTM 11 material. At lower strain rates, the ASTM 11 material demonstrates longer life, possibly due to improved material cleanliness.

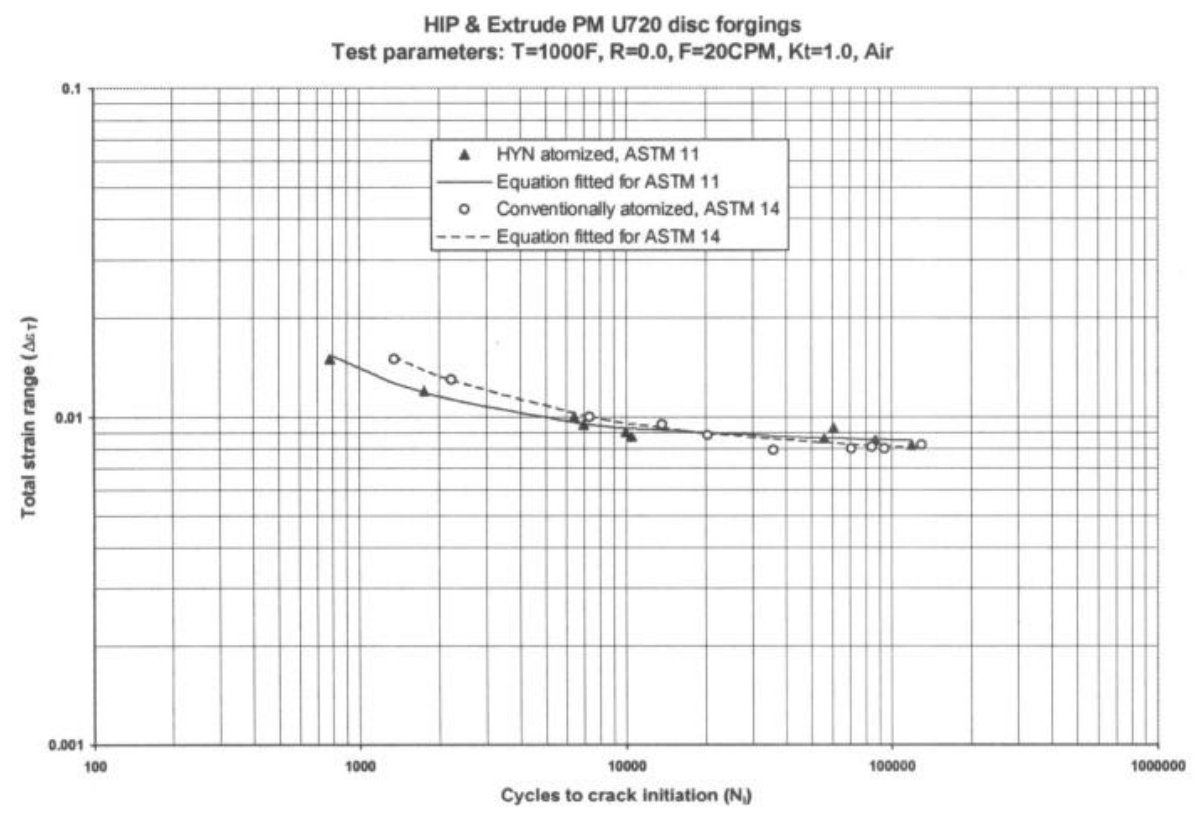

Figure 6. The difference in fatigue life at the higher strains can be attributed to the intentionally coarser grain size obtained by heat treatment. 
An analysis of the fracture initiation sites performed on the LCF specimens show significant differences between the conventional atomized powder and the HYN atomized material. Table III compares the fracture initiation types and locations for both materials. As expected, the -270 mesh HYN material displays fewer non-metallic inclusions at the initiation sites. The predominant initiation feature for the -150 mesh conventionally atomized material, microporosity, is not evident in the HYN material as a result of the finer powder size. Only a few percent of the HYN specimens failed at non-metallic inclusions. The remaining HYN fatigue specimens failed at surface features, which is what one would expect for a very clean material. Another indication of material cleanliness is the fracture initiation location, also indicated in Table III. Only $2 \%$ percent of the initiation sites in the HYN material occurred internally, as compared with $16 \%$ internal initiation sites in the conventionally atomized material. The reduction in internal initiation sites is associated with fewer internal anomalies and is reflective as cleaner material. This information confirms the improved LCF capability of the HYN material.

Table III The initiation sites in the HYN material appears significantly cleaner when evaluating fracture initiation sites of fatigue samples.

\begin{tabular}{|l|c|c|c|c|}
\hline \multicolumn{2}{|c}{} & $\begin{array}{c}\text { Conv. } \\
\text { Atom. } \\
-150\end{array}$ & $\begin{array}{c}\text { HYN } \\
\text { Atom. } \\
-270\end{array}$ \\
\hline $\begin{array}{l}\text { Initiation } \\
\text { Site Type }\end{array}$ & Type I & Discrete & $8 \%$ & $2 \%$ \\
\cline { 2 - 5 } & Type II & Agglomerated & $15 \%$ & $3 \%$ \\
\cline { 2 - 5 } & Type III & Microporosity & $36 \%$ & $0 \%$ \\
\cline { 2 - 5 } & Type IV & Surface, G.B. & $41 \%$ & $95 \%$ \\
\hline \multirow{3}{*}{ Location } & All Types & Internal & $16 \%$ & $2 \%$ \\
\cline { 2 - 5 } & All Types & Surface & $84 \%$ & $98 \%$ \\
\hline
\end{tabular}

Fatigue crack growth rate testing was conducted at $1200^{\circ} \mathrm{F}, \mathrm{R}=0.05$ and $10 \mathrm{~Hz}$. Again the results are compared with conventionally atomized ASTM 14 material in Figure 7. The improvement in performance of coarser grain material is evident in the order of magnitude improvement in crack growth rate of the ASTM 11 material versus the ASTM 14 material. This trend is considered favorable for newer engine designs, which rely on damage tolerance as a major criteria for satisfying life requirements of critical rotating components.

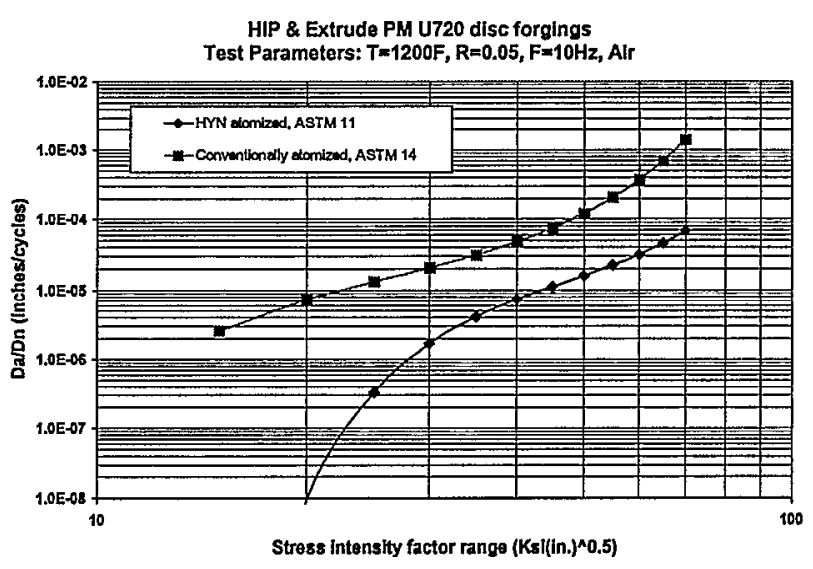

Figure 7 The uniform ASTM 11 grain size in the HYN material provided significantly improved fatigue crack growth response.

The advanced HYN powder process route provides a significant reduction in processing costs compared to traditional powder practices. In addition, the need for specialized extrusion equipment and high set-up costs is not required with the reduced extrusion ratios. When this approach for lower cost billet is coupled with near-net shape isothermal forging, significant cost reductions can be realized for forged components. Based on this information, Rolls-Royce Allison is aggressively pursuing these technologies for implementation in a wide range of engine applications.

\section{$\underline{\text { Conclusions }}$}

1) Standard test practices for water elutriation testing resulted in extraneous inclusions when applied to the -270 mesh product.

2) Ceramic materials present in the powder and billet material produced using the high yield nozzle atomization process were similar in composition and lower in frequency to those present in conventional atomized product.

3) HIP plus low extrusion ratio (3:1) billet product was microstructurally and ultrasonically similar to conventional produced using a high extrusion ratio (6:1).

4) Isothermally forged PM UDIMET Alloy 720 material processed to a grain size of ASTM 11 exhibits attractive levels of elevated temperature tensile, low cycle fatigue and fatigue crack growth rate properties, capable of mccting low pressure turbine disk design requirements. 


\section{Acknowledgements}

This work was performed under U.S. Navy Prime Contract No. N00140-92-C-BC49 at the National Center for Excellence in Metalworking Technology operated by Concurrent Technologies Corporation, under the direction of Dr. Gary Miller. The NAVAIR technical monitor was Dr. George Richardson. Technical assistance was provided by Karen Sellitti at Special Metals Corporation, Dr. Chi-An Yin and Mr. Dennis Overshiner at RollsRoyce Corporation and Mr. Joe Lemsky at Ladish Co., Inc.

${ }^{1}$ J. B. Moore and R. L. Athey, U.S. Patent 3,519,503, (1970).

${ }^{2}$ J.C. Murray, P. G. Roth, J. E. Morra and J. M. Hyzak, APMI / MPIF Conference, 1994.

${ }^{3}$ G. Miller, Workshop on High Temperature Structural Alloys, West Virginia University, May 19-21, 1999.

${ }^{4} \mathrm{~K}$. A. Green, J. A. Lemsky, and R. M. Gasior,

"Development of Isothermally Forged P/M Udimet 720

for Turbine Disk Applications", Superalloys 1996

(Warrendale, PA: TMS, 1996), 697-703. 